\title{
Supply Chain Decision Analysis Based on Risk-Aversion and Cost Information Asymmetry
}

\author{
Sijia Xiong1, Liyang Xiong ${ }^{2 *}$ \\ ${ }^{1}$ School of Management, Department of Business Administration, Jinan University, Guangzhou, China \\ ${ }^{2}$ School of Economics, Management, and Law, University of South China, Hengyang, China \\ Email:^xsja@foxmail.com
}

How to cite this paper: Xiong, S.J. and Xiong, L.Y. (2019) Supply Chain Decision Analysis Based on Risk-Aversion and Cost Information Asymmetry. Journal of Service Science and Management, 12, 439-450. https://doi.org/10.4236/jssm.2019.123030

Received: March 15, 2019

Accepted: April 19, 2019

Published: April 22, 2019

Copyright () 2019 by author(s) and Scientific Research Publishing Inc. This work is licensed under the Creative Commons Attribution International License (CC BY 4.0).

http://creativecommons.org/licenses/by/4.0/

\section{c) (i) Open Access}

\begin{abstract}
This paper analyzes the impact of risk aversion and retailer's cost lied factor on supply chain decision-making in a hybrid channel supply chain system consisting of a risk-averse manufacturer and a retailer. According to the expected utility maximization theory, this paper gets the optimal decision of the manufacturer and retailer. First, it analyzes the impact of risk aversion factor on pricing decisions of supply chain members when the information of the retailer's cost is public. Next, this paper considers the fact that the retailer has advantages on cost information, analyzes the relations between the retailer's optimal cost lied factor and each parameter.
\end{abstract}

\section{Keywords}

Hybrid Channel Supply Chain, Risk Aversion, Retailer Cost Information Asymmetry, Lied Factor

\section{Introduction}

With the rapid development of e-commerce, more and more manufacturing companies have established direct sales channels, forming a mix of channels with traditional retail channels, such as Midea and Gree Electric Appliances, in order to enhance corporate competitiveness and increase product sales. The difference between the supply chain under the hybrid channel and the traditional supply chain is that the former can directly sell products to consumers, the manufacturer and the retailer form a cooperative and competitive relationship. In the hybrid channel supply chain, the supply chain members have different cost and demand information, which will have a crucial impact on the member's 
decision-making behavior and the benefit of the supply chain. Therefore, setting a reasonable information sharing mechanism is important and necessary. According to the principal-agent model, agents usually conceal private information in order to obtain more benefits. Similarly, supply chain members will conceal or misrepresent relevant information in order to maximize their own interests. For example, manufacturers may lie about cost information, and retailers may lie about demand information. This paper mainly studies the impact of supply chain member information asymmetry on the member's pricing decisions in the case of risk aversion.

This study considers a hybrid supply chain setting with a dominant manufacturer and a retailer who possesses cost information advantage. The retailer will lie to manufacturer about costs. The Stackelberg game model is used to establish the sequence of events between the manufacturer and the retailer. The manufacturer first offers a wholesale price contract to the retailer, and the retailer decides order quantity and retail price. The rest of the paper is organized as follows. In Section 2, we conduct a literature review. In Section 3, we introduce the parameters and assumptions of the model, and the Stackelberg game model with manufacturer as the dominant one, retailer's marginal cost is public information. In Section 4, we analyze the Stackelberg game model with the retailer's marginal cost that is private information. In Section 5, we draw the conclusion and some suggestions for future research.

\section{Literature Review}

At present, domestic and foreign scholars have some academic achievements on the research of hybrid channel supply chain, but most of the research adopts the complete rational hypothesis. However, in practice activities, behavioral factors have important impacts on the decision-making behavior of supply chain members, such as risk aversion. Chiang and Chhajed studied the dual channel pricing decision problem under the condition of demand determination. Then, they pointed out that manufacturers could influence retailers' pricing decisions through direct marketing channel, and the double-marginal utility is decreasing [1]. Wang and Webster explored whether risk aversion would lead to higher retailer retail prices and less orders [2]. Seyed Esfahani and Biazaran found that the order quantity of goods is affected by the risk preference and fairness preference of the members in the system [3]. Arcelus and Kumar found that in a single-channel supply chain system, risk aversion reduces sales and redistributes profits between retailers and manufacturers [4]. Ma and Zhang found an optimal pricing strategy in a hybrid channel supply chain system consisting of risk-averse retailers and risk-neutral manufacturers [5]. Li and Hou analyzed the impact of retailer's risk aversion on pricing and order volume in supply chain system [6].

In the supply chain system, there are many phenomena of information asymmetry. The information asymmetry of members will lead to the two parties not 
being able to make the most effective decisions, as well as disrupting supply chain coordination and reducing supply chain efficiency. In view of the information asymmetry in the supply chain system, scholars have made specific analysis on specific problems. Cachon studied the asymmetry of market demand information between the buyer and the seller, and the buyer showed the real market demand information to the seller by designing the contract menu [7]. Ha studied the supply chain coordination problem of the buyer's cost information for both public and private information [8]. Esmaeili analyzed the situation where the buyer has demand information and the seller has purchase cost information in the supply chain system [9].

There are some related researches on the cost information asymmetry of supply chain members. In the context of asymmetric buyer cost information, Corbett and Groote analyzed the optimal quantity discount contract that the seller can provide [10]. Lau studied manufacturers with the advantage of production cost information in a two-echelon system [11]. Moreover, Lau established the Stackelberg game model in which the manufacturer's production cost was private information and the retailer dominated the game, the retailer provided a reverse quantity discount contract, and finally confirmed the validity of the contract [12]. Yao and Yue studied the influence of information sharing mechanism on channel decision-making in view of asymmetric information of service cost [13], in addition, in the supply chain system where the supplier is a leader and buyer cost information asymmetry. Wang and Yang found that the supplier's understanding of buyer cost information has an impact on the decision-making and performance of supply chain members [14].

Although there are many research results in the information asymmetry in the supply chain system, most of the researches discuss the impact of asymmetric information on the optimal decision-making behavior of supply chain members from the risk aversion behavior factors or cost information. Moreover, most of the research on supply chain coordination under information asymmetry establishes a single-channel two-level supply chain, which is not match the actual situation of most enterprises as a hybrid channel supply chain. In the actual operation of the enterprises, the retailer's private cost information will also affect the ordering decisions, such as inventory holding costs and product reprocessing costs. Whether the retailer has the information advantage, or the manufacturer has the information advantage, the party with the information advantage may lie about the information and influence the supply chain's performance in order to maximize utility. Therefore, this paper considers the retailer's private information cost, and analyzes the impact of risk aversion coefficient and retailer cost lied factor on the decision-making behavior of supply chain members in the hybrid channel supply chain of risk aversion.

\section{The Stackelberg Game Model with Symmetric Information}

The supply chain model discussed in this paper is shown in Figure 1. The 


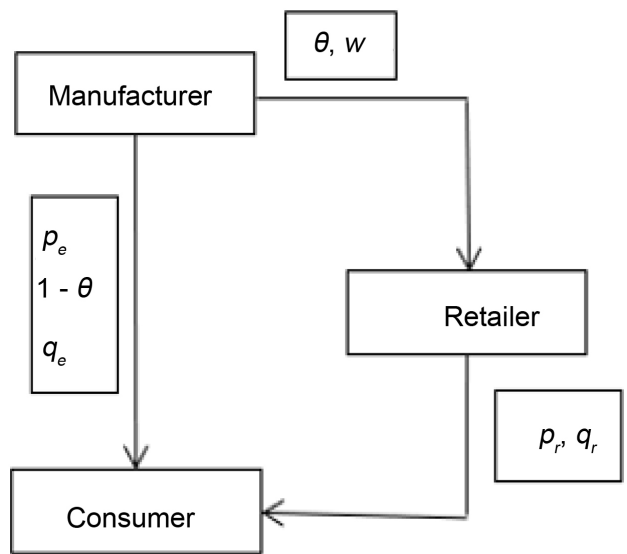

Figure 1. The hybrid channel supply chain.

manufacturer is leader in the two-level supply chain, and he has two sales channels: 1) direct sales channels; 2) distribution channels. The wholesale price is $w$, retail prices for direct and distribution channels are $p_{e}$ and $p_{r}$, the sales volume under direct and distribution channels is $q_{e}$ and $q_{r}$ respectively. $m$ is the marginal cost of the retailer's private information, $\lambda$ is the cost lied factor, and $c$ is the manufacturer's marginal cost of production.

Assume that the total market demand is $A=a+\delta, \delta \sim\left(0, \sigma^{2}\right)$. And $a$ is the basic market demand scale, $\delta$ is the random variable of market demand fluctuation. The sales volume of the distribution channel accounts for $\theta$ proportion of the total market demand, $0 \leq \theta \leq 1$.

This paper considers that both manufacturers and retailers are risk averse, where $\eta_{e}$ and $\eta_{r}$ respectively represent the risk aversion factors.

Utility function is $U(\pi)=E(\pi)-\eta \sqrt{\operatorname{Var}(\pi)}$, where $\eta$ is the risk aversion factors, and $\eta \geq 0$. When $\eta=0$, the market decision maker is risk neutral.

The sales volume of direct sales channel $q_{e}$ and distribution channel $q_{r}$ are:

$$
\begin{aligned}
& q_{e}=(1-\theta) A-p_{e}+k\left(p_{r}-p_{e}\right) \\
& q_{r}=\theta A-p_{r}+k\left(p_{e}-p_{r}\right)
\end{aligned}
$$

where $k$ is the price cross sensitivity coefficient, and $0<k<1$.

In the Stackelberg game model with manufacturer as the dominant one, retailer's marginal cost is public information. The game model is divided into two stages: in the first stage, the manufacturer decides the wholesale price and the selling price of the direct channel. Then, in the second stage, the retailer decides the retail price of the traditional retail channel. According to the relationship between demand and price, we can know that determining price is equivalent to determining sales volume. Therefore, it can be known that the retailer's expected profit is $E\left(\pi_{r}\right)$ :

$$
E\left(\pi_{r}\right)=\left(p_{r}-w-m\right) q_{r}=\left(p_{r}-w-m\right)\left[\theta A-p_{r}+K\left(p_{e}-p_{r}\right)\right]
$$

Considering that the retailer is risk-averse, then, his utility function is $U_{r}\left(\pi_{r}\right)$ : 


$$
\begin{aligned}
U_{r}\left(\pi_{r}\right) & =\left(p_{r}-w-m\right)\left[\theta A-p_{r}+K\left(p_{e}-p_{r}\right)\right]-\eta_{r} \sqrt{\operatorname{Var}\left(\pi_{r}\right)} \\
& =\left(p_{r}-w-m\right)\left[\theta A-p_{r}+K\left(p_{e}-p_{r}\right)\right]-\eta_{r} \theta \sigma\left(p_{r}-w-m\right)
\end{aligned}
$$

The derivative of the retailer's utility function with the retail price $p_{r}$ can be obtained as follows.

$$
\begin{aligned}
& \partial U_{r}\left(\pi_{r}\right) / \partial p_{r} \\
& =\theta A-2 p_{r}-2 k p_{r}+k p_{e}+(1+k)(m+w) \\
& -\eta_{r} \theta \sigma * \partial^{2} U_{r}\left(\pi_{r}\right) / \partial p_{r}^{2}-2-2 k<0
\end{aligned}
$$

Obviously, the second derivative of the utility function with respect to the retail price is less than 0 , indicating that the retailer has a unique optimal pricing decision $p_{r}^{*}$.

$$
p_{r}^{*}=\left(\theta A+k p_{e}-\eta_{r} \theta \sigma\right) /(2+2 k)+(w+m) / 2
$$

By analyzing the Equation (4) of the optimal retail price, it is found that the optimal retail price of the traditional retail channel will increase with the wholesale price $w$ and the direct price $p_{e}$, and the retail price also increases with the retailer's marginal cost $m$. In addition, the optimal retail price decreases with the retailer's risk aversion $\eta_{r}$

Then, the manufacturer will determine the best wholesale price and the best direct price according to the retailer's best retail price. First, the manufacturer's expected revenue function and utility function expressions are obtained: $E\left(\pi_{e}\right)$ and $U_{e}\left(\pi_{e}\right)$

$$
\begin{aligned}
E\left(\pi_{e}\right)= & \left(p_{e}-c\right) q_{e}+(w-c) q_{r} \\
= & \left(p_{e}-c\right)\left[(1-\theta) A-p_{e}+k\left(p_{r}-p_{e}\right)\right] \\
& +(w-c)\left[\theta A-p_{r}+k\left(p_{e}-p_{r}\right)\right] \\
U_{e}\left(\pi_{e}\right)= & \left(p_{e}-c\right)\left[(1-\theta) A-p_{e}+k\left(p_{r}-p_{e}\right)\right] \\
& +(w-c)\left[\theta A-p_{r}+k\left(p_{e}-p_{r}\right)\right] \\
& -\eta_{e} \sigma\left[\left(p_{e}-c\right)(1-\theta)+(w-c) \theta\right]
\end{aligned}
$$

The manufacturer's utility function differentiates the wholesale price $w$ and the direct price p respectively:

$$
\begin{aligned}
& \partial U_{e}\left(\pi_{e}\right) / \partial w=k p_{e}+\left(\theta A+\eta_{r} \theta \sigma+c\right) / 2-\eta_{e} \theta \sigma-w(1+k)-m(1+k) / 2 \\
& \partial U_{e}\left(\pi_{e}\right) / \partial p_{e}=(1-\theta) A+c+c k /(2+2 k)-\eta_{e} \sigma(1-\theta) \\
& +k \theta\left(A-\eta_{r} \sigma\right) /(2+2 k)+k m / 2+w k \\
& -p_{e}\left(k^{2}+4 k+2\right) /(1+k) \\
& \partial^{2} U_{e}\left(\pi_{e}\right) / \partial w^{2}=-(1+k)<0 \\
& \partial^{2} U_{e}\left(\pi_{e}\right) / \partial p_{e}^{2}=-\left(k^{2}+4 k+2\right) /(1+k)<0
\end{aligned}
$$

Since the second derivative is less than 0 , it can know that there exists a unique optimal solution for both wholesale price and direct price. The above formula can be used to obtain the manufacturer's optimal wholesale price $w^{*}$ 
and optimal direct selling price $p_{e}^{*}$.

$$
\begin{gathered}
w^{*}=k *\left[(1-\theta) A+c-\eta_{e} \sigma(1-\theta)+\left(k \theta A-k \theta \eta_{r} \sigma+c k\right) /(2+2 k)\right. \\
+k m / 2] /(4 k+2)+\left(k^{2}+4 k+2\right) \\
*\left[\left(\theta A+\theta \eta_{r} \sigma+c-2 \eta_{e} \sigma \theta\right) /(2+2 k)-m / 2\right] /(4 k+2) \\
p_{e}^{*}=\left[(1-\theta) A+c+\left(k \theta A-k \theta \eta_{r} \sigma+c k\right) /(2+2 k)-\eta_{e} \sigma(1-\theta)+k m / 2\right]+w^{*} k
\end{gathered}
$$

Proposition 1: In the hybrid channel supply chain where the retailer's cost is public information, exist: $\partial p_{r}^{*} / \partial \eta_{r}<0, \partial p_{r}^{*} / \partial \eta_{e}<0, \partial w^{*} / \partial \eta_{r}>0$, $\partial w^{*} / \partial \eta_{e}<0, \partial p_{e}^{*} / \partial \eta_{r}=0, \partial p_{e}^{*} / \partial \eta_{e}<0$.

It's easy to see that the optimal retail price of retailer is decreasing in the risk aversion factors of retailer and manufacturer. The manufacturer's optimal wholesale price is increasing in the retailer's risk aversion factor and decreasing in the manufacturer's risk aversion factor. The optimal direct selling price is decreasing in the risk aversion factors of manufacturer, and not affected by retailer's risk aversion.

Proof: The optimal retail price, the optimal wholesale price and the optimal direct selling price were differentiated with respect to the risk aversion factors of retailer and manufacturer, and the following results can be obtained:

$$
\begin{aligned}
\partial p_{r}^{*} / \partial \eta_{r}= & -\theta \sigma /(4+4 k)<0 \\
\partial p_{r}^{*} / \partial \eta_{e}= & -\sigma(1-\theta)-k \sigma(1-\theta) /(4 k+2) \\
& -\theta \sigma\left(k^{2}+4 k+2\right) /[(1+k)(4 k+2)]<0 \\
\partial w^{*} / \partial \eta_{r}= & \theta \sigma /(2+2 k)>0 \\
\partial w^{*} / \partial \eta_{e}= & -k \sigma(1-\theta) /(4 k+2)-\theta \sigma\left(k^{2}+4 k+2\right) /[(1+k)(4 k+2)]<0 \\
\partial p_{e}^{*} / \partial \eta_{r}= & 0 \\
\partial p_{e}^{*} / \partial \eta_{e}= & -\sigma(1-\theta)-k \sigma(1-\theta) /(4 k+2) \\
& -\theta \sigma\left(k^{2}+4 k+2\right) /[(1+k)(4 k+2)]<0
\end{aligned}
$$

\section{The Model with Asymmetric Cost Information}

In the hybrid channel supply chain, the retailer's marginal cost is private information, and the retailer will determine the appropriate cost lied factor $\lambda$ in order to maximize his utility. This means that the retailer's marginal cost of public disclosure is $\lambda m$. When $\lambda>1$, the retailer is over-reporting marginal cost information, or $\lambda=1$, the retailer is not lying about marginal cost information, or $\lambda<1$, the retailer is under-reporting marginal cost information. In this case, the manufacturer can only decide the wholesale price and direct selling price according to the cost information disclosed by the retailer and the retailer's pricing and ordering decisions. When the retailer conceals its true cost information, the decision variable is denoted with $N$.

The retailer's public utility function is $U_{r}^{N}\left(\pi_{r}^{N}\right)$

$$
U_{r}^{N}\left(\pi_{r}^{N}\right)=\left(p_{r}^{N}-w^{N}-\lambda m\right)\left[\theta A-p_{r}^{N}+k\left(p_{e}^{N}-p_{r}^{N}\right)\right]-\eta_{r} \theta \sigma\left(p_{r}^{N}-w^{N}-\lambda m\right)
$$


In order to keep consistent with the behavior of false reporting costs, retailers will determine the optimal retail price based on the published cost information while pursuing the utility maximization.

According to the retailer's public utility function, the optimal retail price is $p_{r}^{N *}$.

$$
p_{r}^{N *}=\left(\theta A+k p_{e}-\eta_{r} \theta \sigma\right) /(2+2 k)+(w+\lambda m) / 2
$$

Then, the manufacturer determines the optimal wholesale and direct selling price based on the retailer's public cost information. By differentiating the manufacturer's utility function with the wholesale price and the direct price, it is found that there exists only the optimal wholesale price $w^{N *}$ and the optimal direct selling price $p_{e}^{N *}$.

By substituting $p_{r}^{N *}$ into $w^{N *}$ and $p_{e}^{N *}$, the following results can be obtained.

$$
\begin{gathered}
w^{N *}=k *\left[(1-\theta) A+c-\eta_{e} \sigma(1-\theta)+\left(k \theta A-k \theta \eta_{r} \sigma+c k\right) /(2+2 k)\right. \\
+k \lambda m / 2] /(4 k+2)+\left(k^{2}+4 k+2\right) \\
*\left[\left(\theta A+\theta \eta_{r} \sigma+c-2 \eta_{e} \sigma \theta\right) /(2+2 k)-\lambda m / 2\right] /(4 k+2) \\
p_{e}^{N *}=\left[(1-\theta) A+c+\left(k \theta A-k \theta \eta_{r} \sigma+c k\right) /(2+2 k)\right. \\
\left.-\eta_{e} \sigma(1-\theta)+k \lambda m / 2\right]+w^{N *} k
\end{gathered}
$$

Theorem 1: In the hybrid channel supply chain, the optimal retail price of the retailer with asymmetric cost information, the optimal wholesale price and the direct selling price of the manufacturer are: $p_{r}^{N *}, w^{N *}, p_{e}^{N *}$.

Next, this paper analyzes the impact of retailer cost lied factor on the optimal pricing decision of supply chain members.

Proposition 2: In the hybrid channel supply chain where the retailer's cost is private information, there exist: $\partial p_{r}^{N *} / \partial \lambda>0, \partial w^{N *} / \partial \lambda<0, \partial p_{e}^{N *} / \partial \lambda=0$.

Proposition 2 indicates that when the retailer's cost lie factor is larger, the retail price he sets is higher, and the wholesale price set by the manufacturer will be lower. However, increasing the retail price will reduce the sales volume. Therefore, the retailer needs to determine the optimal cost lied factor based on actual utility.

Proof: The optimal retail price, the optimal wholesale price and the optimal direct selling price are respectively derived from the retailer's cost misstatement factor to obtain the following formula.

$$
\begin{gathered}
\partial p_{r}^{N *} / \partial \lambda=m / 4>0 \\
\partial w^{N *} / \partial \lambda=-m / 2<0 \\
\partial p_{e}^{N *} / \partial \lambda=0
\end{gathered}
$$

According to the above analysis results, the actual total utility functions of retailer, manufacturer and supply chain can be obtained.

$$
\begin{aligned}
U_{r}^{N}\left(\pi_{r}^{N}\right)= & \left(p_{r}^{N *}-w^{N *}-m\right)\left[\theta A-p_{r}^{N *}+k\left(p_{e}^{N *}-p_{r}^{N *}\right)\right] \\
& -\eta_{r} \theta \sigma\left(p_{r}^{N *}-w^{N *}-m\right)
\end{aligned}
$$




$$
\begin{aligned}
U_{e}^{N}\left(\pi_{e}^{N}\right)= & \left(p_{e}^{N *}-c\right)\left[(1-\theta) A-p_{e}^{N *}+k\left(p_{r}^{N *}-p_{e}^{N *}\right)\right] \\
& +\left(w^{N *}-c\right) *\left[\theta A-p_{r}+k\left(p_{e}^{N *}-p_{r}^{N *}\right)\right] \\
& -\eta_{e} \sigma\left[\left(p_{e}^{N *}-c\right)(1-\theta)+\left(w^{N *}-c\right) \theta\right] \\
U_{s c}^{N} & =U_{S}^{N}+U_{r}^{N}
\end{aligned}
$$

Under the condition that the retailer has cost information advantage, he will decide the optimal lied factor to maximize his utility. Similarly, the optimal cost lied factor $\lambda^{*}$ can be obtained by deriving the retailer's actual utility function to the lied factor.

\section{Comparative Statics}

In the model, we use mathematical analysis to investigate retailer and manufacture's optimal decision, and some parameters' influence on the optimal decision. Then, we numerical analyze the relationship between $\lambda^{*}$ and various variables. Figures 2-4 can be obtained through example analysis. Figure 2 shows the influence of retailer's risk aversion factor $\eta_{r}$, with $A=1, m=0.3, c=0.5$, $k=0.5, \theta=0.5$. Figure 3 shows the influence of retailer's real cost $m$, with $A=1, \eta_{r}=0.5, c=0.5, k=0.5, \theta=0.5$. Figure 4 shows the influence of the price cross sensitivity coefficient $k$, with $A=1, m=0.3, c=0.5, \eta_{r}=0.5, \theta=0.5$.

Proposition 3: For parameter changes, the optimal lied factor $\lambda^{*}$ has following characters.

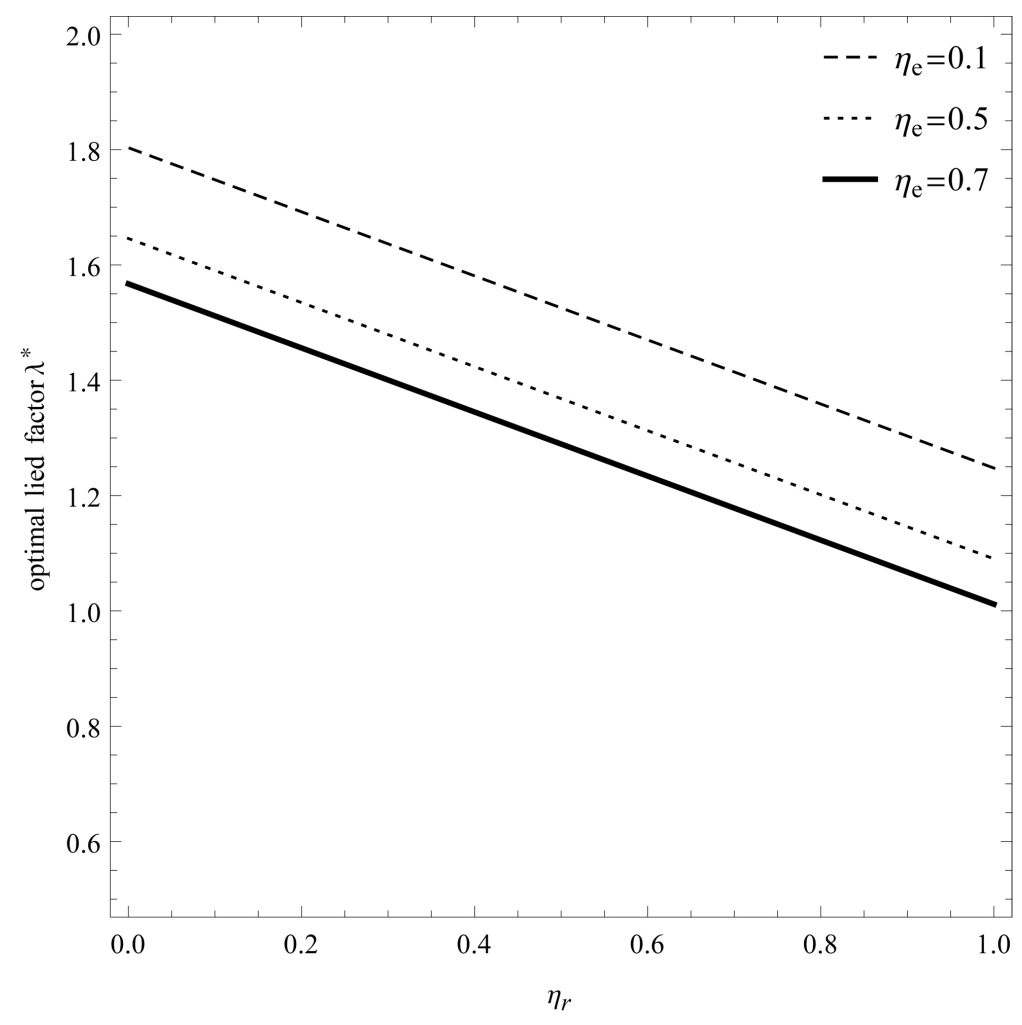

Figure 2. The relationship between $\eta_{r}$ and $\lambda^{*}$. 


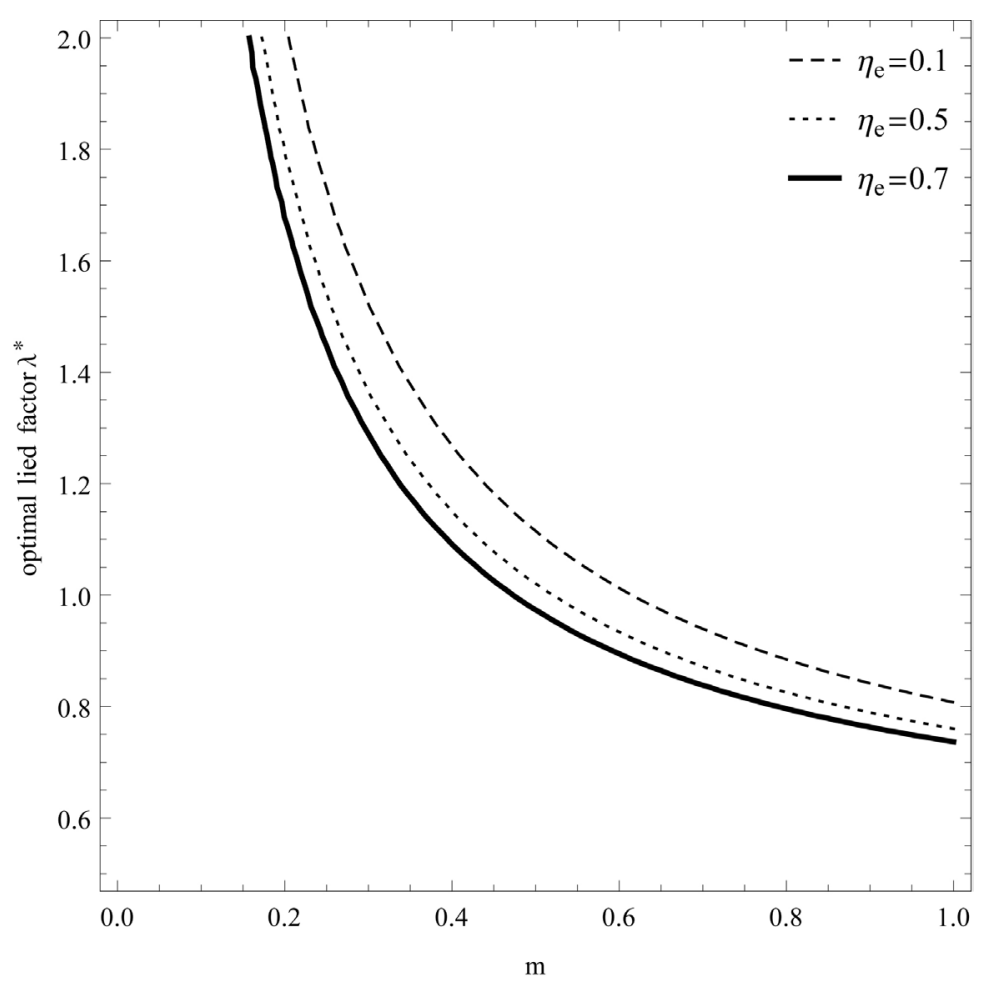

Figure 3. The relationship between $m$ and $\lambda^{*}$.

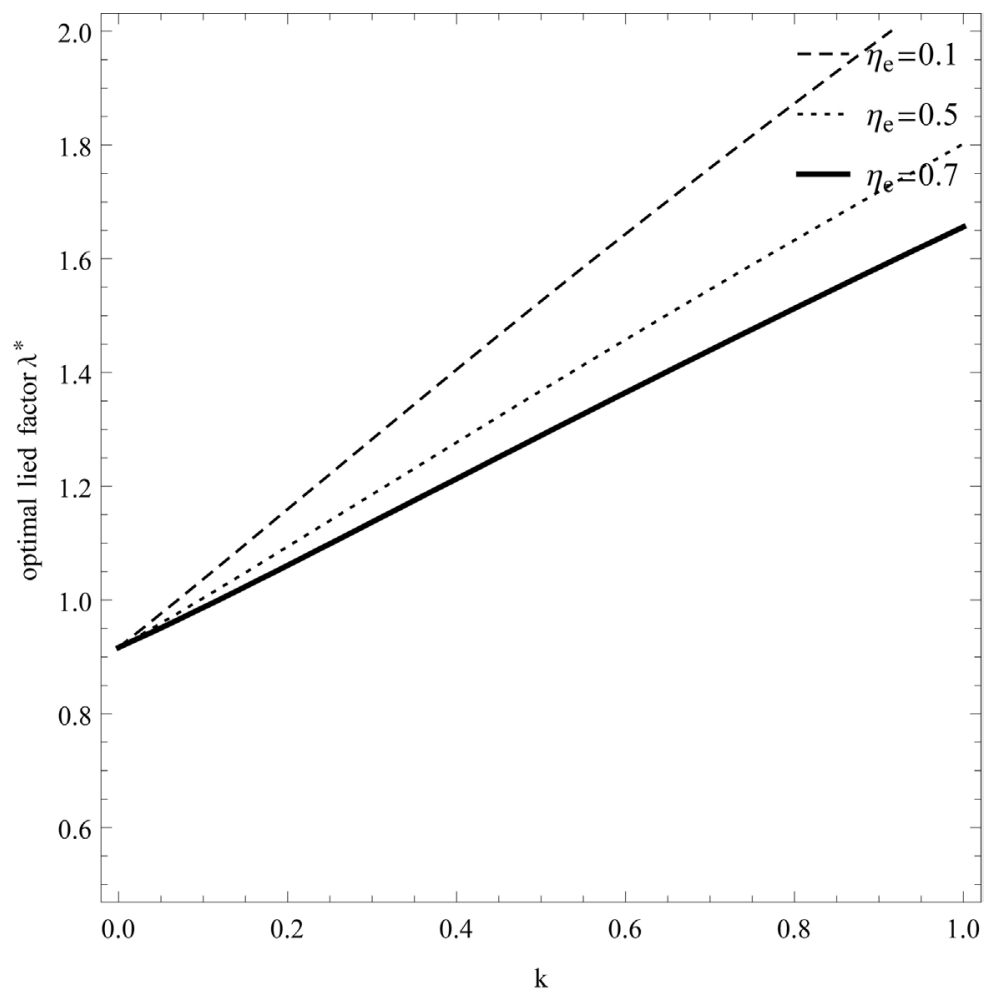

Figure 4. The relationship between $k$ and $\lambda^{*}$.

1) $\lambda^{*}$ is decreasing in $\eta_{r}$ and $\eta_{e}$.

2) $\lambda^{*}$ is decreasing in $m$. 
3) $\lambda^{*}$ is increasing in $k$.

Figure 2 shows that the retailer's optimal cost lied factor $\lambda^{*}$ is negatively correlated with the retailer's risk aversion factor $\eta_{r}$ under three different manufacturer risk aversion factor coefficients $\left(\eta_{e}=0.1 ; 0.5 ; 0.7\right)$. In other words, when the retailer chooses to disclose false cost information, the optimal cost lied factor of the retailer will decrease in the retailer and manufacture's risk aversion factor.

Figure 3 shows that the retailer's optimal cost lied factor $\lambda^{*}$ is negatively correlated with the retailer's real cost $m$. In other words, retailer's optimal cost lied factor is decreasing in his real production cost. Moreover, there is a certain threshold of production cost. When the production cost is lower than the threshold, the retailer's cost lied factor is greater than 1 , indicating that the retailer will overstate the production cost. When the production cost is higher than the threshold, the cost lied factor will be less than 1 .

Similarly, under three different manufacturer risk aversion factor coefficients, Figure 4 shows that the retailer's optimal cost lied factor $\lambda^{*}$ is positively correlated with the price cross sensitivity coefficient $k$. When the retailer chooses to disclose false cost information, the retailer with a higher price cross sensitivity coefficient has a greater lied factor.

\section{Conclusions}

This paper obtains the optimal pricing decision of retailers and manufacturers by establishing a risk-averse hybrid channel supply chain model with retailers' cost information asymmetry. Furthermore, we also analyze the impact of the risk aversion of supply chain members on the optimal pricing strategy, and the impact of retailer's cost lied factors on supply chain member decision variables. The study finds that 1 ) the optimal retail price is decreasing in the retailer and manufacturer's risk aversion factor; 2) the optimal wholesale price is increasing in the retailer's risk aversion factor, but it's decreasing in the manufacturer's risk aversion factor; 3 ) the direct selling price is decreasing in the manufacturer's risk aversion factor, but retailer's risk aversion has no effect on it.

In all, this paper mainly discusses the retailer uses private cost information to choose the optimal cost lied factor to pursue the utility maximization model. In addition to the relationship between the optimal price and risk aversion factor of supply chain members, we also found that the optimal cost lied factor of retailer is negatively correlated with risk aversion degree and production cost, and positively correlated with cross price sensitivity coefficient. In addition, by analyzing the impact of retailers' cost lied behavioral on the pricing decisions of supply chain members, it is found that the optimal retail price is positively correlated with the lied factor, the optimal wholesale price is negatively correlated with the misstatement factor, and there is no correlation between the optimal direct selling price and the lied factor. In general, the retailers' lied behavioral is beneficial to himself but not to the manufacturer. Therefore, manufacturer should take 
measures to encourage retailer to share his cost information.

This paper studies the retailer's cost as private information, and the manufacturer's cost is public information. In the future, we can explore the situation where manufacturer and retailer's costs are private information. In addition, it is also a meaningful research issue to design a reasonable contract coordination mechanism to encourage retailer to share his private cost information actively, thereby improving the overall performance of retailer, supplier and supply chain. Finally, the analysis of this paper is based on the mathematical model, and more in-depth analysis can be done through empirical research.

\section{Conflicts of Interest}

The authors declare no conflicts of interest regarding the publication of this paper.

\section{References}

[1] Chiang, W.K., Chhajed, D. and Hess, J.D. (2003) Direct Marketing, Indirect Profits: A Strategic Analysis of Dual-Channel Supply-Chain Design. Management Science, 49, 1-20. https://doi.org/10.1287/mnsc.49.1.1.12749

[2] Wang, C.X., Webster, S. and Suresh, N.C. (2009) Would a Risk-Averse Newsvendor Order Less at a Higher Selling Price? European Journal of Operational Research, 196, 544-553. https://doi.org/10.1016/j.ejor.2008.04.002

[3] Seyed Esfahani, M.M., Biazaran, M. and Gharakhani, M. (2011) A Game Theoretic Approach to Coordinate Pricing and Vertical Co-Op Advertising in ManufacturEr-Retailer Supply Chains. European Journal of Operational Research, 211, 263-273. https://doi.org/10.1016/j.ejor.2010.11.014

[4] Arcelus, F.J., Kumar, S. and Srinivasan, G. (2012) Risk Tolerance and a Retailer's Pricing and Ordering Policies within a Newsvendor Framework. Omega, 40, 188-198. https://doi.org/10.1016/j.omega.2011.05.007

[5] Ma, L.D., Zhang, R. and Guo, S. (2012) Pricing Decisions and Strategies Selection of Dominant Manufacturer in Dual-Channel Supply Chain. Economic Modelling, 29, 2558-2565. https://doi.org/10.1016/j.econmod.2012.06.012

[6] Li, B., Hou, P.W., Chen, P. and Li, Q.H. (2016) Pricing Strategy and Coordination in a Dual Channel Supply Chain with a Risk-Averse Retailer. International Journal of Production Economics, 178, 154-168. https://doi.org/10.1016/j.ijpe.2016.05.010

[7] Cachon, G.P. and Lariviere, M.A. (2001) Contracting to Assure Supply: How to Share Demand Forecasts in a Supply Chain. Management Science, 47, 629-646. https://doi.org/10.1287/mnsc.47.5.629.10486

[8] Ha, A.Y. (2001) Supplier-Buyer Contracting: Asymmetric Cost Information and Cutoff Level Policy for Buyer Participation. Naval Research Logistics, 48, 41-64. https://doi.org/10.1002/1520-6750(200102)48:1<41::AID-NAV3>3.0.CO;2-M

[9] Esmaeili, M. and Zeephongsekul, P. (2010) Seller-Buyer Models of Supply Chain Management with an Asymmetric Information Structure. International Journal of Production Economics, 123, 146-154. https://doi.org/10.1016/j.ijpe.2009.07.016

[10] Corbett, C.J. and De Groote, X. (2000) A Supplier's Optimal Quantity Discount Policy under Asymmetric Information. Management Science, 46, 444-450. https://doi.org/10.1287/mnsc.46.3.444.12065

[11] Lau, A.H.L., Lau, H.S. and Zhou, Y.W. (2006) Considering Asymmetrical Manufacturing Cost Information in a Two-Echelon System That Uses Price-Only Con- 
tracts. IIE Transactions, 38, 253-271. https://doi.org/10.1080/07408170590961148

[12] Lau, A.H.L., Lau, H.S. and Wang, J.C. (2007) Pricing and Volume Discounting for a Dominant Retailer with Uncertain Manufacturing Cost Information. European Journal of Operational Research, 183, 848-870.

https://doi.org/10.1016/j.ejor.2006.10.017

[13] Yao, D.Q., Yue, X.H. and Liu, J. (2008) Vertical Cost Information Sharing in a Supply Chain with Value-Adding Retailers. Omega, 36, 838-851. https://doi.org/10.1016/j.omega.2006.04.003

[14] Wang, J.C., Yang, L., Wang, Y.Y. and Wang, Z.H. (2018) Optimal Pricing Contracts and Level of Information Asymmetry in a Supply Chain. International Transactions in Operational Research, 25, 1583-1610.

https://doi.org/10.1111/itor.12237 